Revista de Psicología Vol. 39 (2), 2021 (e-ISSN 2223-3733)

\title{
Desplazamiento forzado en Brasil: Experiencias de mujeres atendidas por la asistencia social ${ }^{1}$
}

\author{
Magaly Calderón Uribe ${ }^{2}$, Cristiano Hamann ${ }^{3}$, Adolfo Pizzinato ${ }^{4}$ \\ Universidad Cooperativa de Colombia-Colombia', Universidade Federal \\ Rio Grande do Sul-Brasil,3
}

El presente artículo buscó comprender lo que entienden mujeres desplazadas, cabezas de familia, atendidas por la Asistencia Social de Brasil, sobre su proceso de desplazamiento y la actuación del Estado frente a este. A través del Análisis Crítico del Discurso se identificó que, aunque son varias las atribuciones causales al desplazamiento - como el riesgo ambiental y la violencia - lo que realmente atraviesa las experiencias de estas mujeres es una urbanización excluyente, vivida a lo largo de la historia de estas familias, que las llevó a una ocupación de espacios inapropiados para vivir, como la orilla de arroyos y terrenos no aptos, que terminaron siendo riesgosos y desalojando a las familias a mediano plazo. Esa situación fue entendida por las participantes cómo un proceso natural a su condición social, pero no como un resultado de la negligencia por parte del Estado. Los resultados indican aun que las formas de desplazamiento forzado están articuladas y que el desplazamiento ambiental sirve como una retórica estatal para justificar desplazamientos relacionados con históricos de violencia y negligencia por parte del Estado.

Palabras clave: desplazamiento, violación de derechos, familias, Estado, desigualdad social.

1 El proyecto mayor al que estuvo vinculado esta investigación pasó por la apreciación de la comisión científica de la Facultad de Psicología, la cual después lo envió a análisis al Comité de Ética en investigación con seres humanos de la Pontificia Universidade Católica do Rio Grande do Sul (PUCRS) (CEP/PUCRS, Parecer Nº12842113.5.0000.5336). Dentro de las familias convidadas a participar de la investigación solo fueron parte del estudio, aquellas que aceptaron y firmaron el término de consentimiento informado y para mantener el anonimato de cada participante, fueron utilizados nombres ficticios en sus identificaciones.

2 Magíster en Psicología Social. Docente en la Universidad Cooperativa de Colombia, Colombia. Dirección postal: Cra 30\# 20-47 Bucaramanga-Colombia. Contacto: maquical@ gmail.com https://orcid.org/0000-0002-5053-9851

3 Magíster en Psicología Social. Alumno de Doctorado en la Universidade Federal Rio Grande do Sul, Brasil. Dirección postal: Rua Ramiro Barcellos, 2600 - Instituto de Psicología - Universidade Federal do Rio Grande do Sul - Porto Alegre (RS) - Brasil. Contacto: cristiano. hamann@gmail.com https://orcid.org/0000-0002-1947-6936

4 Doctor en Psicología Evolutiva. Profesor-investigador de la Universidade Federal Rio Grande do Sul, Brasil. Dirección postal: Rua Ramiro Barcellos, 2600. Contacto: adolfopizzinato@ hotmail.com https://orcid.org/0000-0002-1777-5860 
Forced displacement in Brazil: Experiences from women treated by Social Assistance This article sought to understand what displaced women, heads of families assisted by the Social Assistance of Brazil, understand about their displacement process and the State's actions in regards to it. Through Critical Discourse Analysis it was identified that, although there are several causal attributions to displacement - such as environmental risk and violence - what really runs through the experiences of these women is an exclusionary urbanization, lived throughout the history of these families, which led them to occupy inadequate living spaces such as stream banks and unsuitable land, which ended up being risky and displacing the families in the medium term. Participants understood this situation as a process natural to their social condition, but not as a result of negligence on the part of the State. The results further indicate that the forms of forced displacement are articulated and that environmental displacement serves as State rhetoric to justify displacements related to historical violence and negligence on the part of the State.

Keywords: displacement, violation of rights, families, State, social inequality.

Deslocamento forçado no Brasil: vivências de mulheres atendidas pela assistência social Este artigo buscou compreender o que as mulheres deslocadas, chefes de família, assistidas pela Assistência Social do Brasil, entendem sobre o seu processo de deslocamento e as açóes do Estado contra ele. Por meio da Análise Crítica do Discurso identificou-se que, embora existam várias atribuiçóes causais ao deslocamento - como risco ambiental e violência - o que realmente perpassa as vivências dessas mulheres é uma urbanização excludente, vivida ao longo da história dessas famílias, que as levou a ocuparem espaços inadequados para morar, como margens de riachos e terrenos inadequados, o que acabou gerando mais risco e desalojando as famílias a médio prazo. Essa situação foi entendida pelas participantes como um processo natural de sua condição social, mas não como resultado de um descaso por parte do Estado. Os resultados indicam que as formas de deslocamento forçado são articuladas e servem à retórica estatal para justificar deslocamentos relacionados à violência histórica e negligência por parte do próprio Estado.

Palavras-chave: deslocamento, violação de direitos, famílias, Estado, desigualdade social.

Déplacement forcé au Brásil: expériences des femmes assistées par l'assistance sociale Cet article cherchait à comprendre ce que les femmes déplacées, chefs de famille, aidés par l'assistance sociale du Brésil, comprennent de leur processus de déplacement et des actions de l'État contre lui. Grâce à l'analyse critique du discours, il a été identifié que, bien qu'il y ait plusieurs attributions causales au déplacement - telles que le risque environnemental et la violence - ce qui traverse réellement les expériences de ces femmes est une urbanisation exclusive, vécue tout au long de l'histoire de ces familles, qui a conduit à occuper des espaces de vie inappropriés, tels que les berges des ruisseaux et des terrains inadaptés, qui finissent par être risqués et déloger les familles à moyen terme. Cette situation a été comprise par les participants comme un processus naturel de leur condition sociale, mais non comme le résultat d'une négligence de la part de l'État. Les résultats indiquent également que les formes de déplacement forcé sont articulées et servent de rhétorique étatique pour justifier les déplacements liés à des histoires de violence et de négligence de la part de l'Etat. Mots clés: déplacement, violation des droits, familles, État, inégalités sociales. 
La palabra migración es sinónimo de situaciones relacionadas a la movilización de personas, asociada a la búsqueda de mejores oportunidades y utilizada, en general, para referirse a los grandes movimientos de personas entre fronteras (ACNUR, 2015). Entretanto, los informes estadísticos sobre poblaciones vulnerables a nivel mundial y estudios actuales en diferentes áreas del conocimiento (PNUD, 2018) demuestran la necesidad de analizar las particularidades de los procesos migratorios, atendiendo las dimensiones intranacionales. Investigaciones apuntan que esa temática carece de estudios volcados hacia la experiencia de ajuste al ambiente de acogida, a aspectos socioculturales envueltos en ese proceso, su relación con la garantía de derechos sociales y la promoción de políticas públicas que atiendan la singularidad de las movilizaciones migratorias de determinados contextos (Guerrero, 2016).

Esta es una temática que se ha incrementado en la producción científica brasileña, tradicionalmente enfocada en el desplazamiento de poblaciones en las regiones más pobres, quienes se movilizan hacia los grandes centros urbanos por razones económicas (Carvalho \& Martins, 2016), mostrando resultados de estudios internacionales que indican el gran impacto en la salud (Siriwardhana \& Stewart, 2013), así como la necesidad de poner énfasis en factores culturales y familiares (Daure, Reyverand-Coulon, \& Forzan, 2014). Además de la necesidad de más estudios de migración que evidencien las singularidades de los sistemas de movilidad humana y sus impactos psicosociales (Guerrero, 2016) en especial tendiendo a las particularidades de los desplazamientos forzados en una región como la de Porto Alegre, en el sur de Brasil, región que no cuenta con muchos estudios en el área.

\section{Desplazamiento forzado}

Para el Alto Comisionado de las Naciones Unidas para los Refugiados (ACNUR), es emigrante quien escoge desplazarse no por causa 
de una amenaza directa, sino que busca un futuro mejor, trabajo, educación u otro. Los refugiados, a su vez, son aquellas personas que huyen de conflictos en sus países y cruzan una frontera internacional, no pudiendo volver a su país y quedando bajo las leyes establecidas en el país de acogida para su protección (ACNUR, 2014). Por otro lado, están los desplazados internos, aquellos que tuvieron que movilizarse forzadamente sin cruzar alguna frontera internacional, es decir, que permanecen oficialmente bajo la protección de los gobiernos de sus países, así en ocasiones, las acciones de estos gobiernos sean la causa propia de la violencia que llevó a la migración (Pacheco-Coral, 2018; Ramos Vidal, 2018).

El desplazamiento interno en las regiones de un país puede tomar diversas formas. Puede ser directo, es decir, forzoso e impuesto a los hogares a través de medios violentos como desalojos y embargos, o indirecto, vinculado a las fuerzas económicas y sociales más amplias que producen cambios tan profundos en los barrios que los residentes no pueden permitirse ya vivir ahí o no se identifican ya con su lugar de residencia (Alexandri, González \& Hodkinson, 2016). ACNUR a través del observatorio de desplazamiento interno (Internal Displacement Monitoring Centre - IDMC) señala dos características que identifican este tipo de desplazamiento: el carácter coercitivo que lleva a las personas a abandonar sus hogares (como los conflictos armados, violencia, violaciones de derechos humanos y desastres naturales) y el carácter territorial, es decir que suceda el desplazamiento al interior de las fronteras nacionales, donde es responsabilidad del Estado velar porque estas personas accedan a los mismos derechos que el resto de la población (ACNUR, 2014).

Esa dimensión analítica, señala al desplazamiento forzado como forma singular de migración, que se ha dado como respuesta hacia la creciente ola de migraciones relacionadas con acciones violentas. Datos del 2015 señalan la amplitud de esas cuestiones, e investigaciones del 2016 apuntan para una cifra de 63.3 millones de personas en situación de desplazamiento forzado en el mundo (UNHCR, 2016). Esos datos permiten reconocer la rápida aceleración del desplazamiento en 
los últimos años, convirtiéndolo en un fenómeno que lleva a miles de personas a huir de sus hogares, como consecuencia de diferentes conflictos sociales, políticos y geográficos intrínsecamente relacionados a la postura estatal. Según Tomé y Casillas (2016), desde mediados de los 80 s, el término de "desplazados inducidos por el desarrollo" viene desarrollándose como una categoría válida para analizar las consecuencias sociales de migraciones forzosas derivadas de la construcción de infraestructuras públicas.

\section{El Desplazamiento Forzado en Brasil}

Entre las décadas de 1960 y 1980 ocurrieron intensos movimientos migratorios internos en Brasil, en los que grandes volúmenes de personas se desplazaron del campo a la ciudad, lo que intensificó la urbanización y la delimitación de áreas que expulsaban y áreas que atraían o recibían personas, es el caso de São Paulo y Rio de Janeiro que se volvieron áreas de recepción, contrario a las regiones del Nordeste, Espíritu Santo, Santa Catarina y Rio Grande del Sul que fueron consideradas áreas de expulsión (Do Nascimento et. al, 2018). Esas concentraciones se caracterizaron por comportamientos de acumulación de bienes y servicios típicos de un desarrollo capitalista, en el que el Estado aparece con políticas posicionadas estratégicamente a favor del capital.

La posición procapital del Estado brasileño llevó a una reestructuración del desarrollo político/social, formando una ola de desplazamientos compulsivos que violaron los derechos humanos, en especial el derecho a la vivienda (Cardoso et.al., 2017). Y de acuerdo con la Declaración Universal de los Derechos Humanos, el derecho a la vivienda adecuada es reconocido internacionalmente, es decir, que se aplica en todas las partes del mundo, a todas las personas, donde el Estado tiene la obligación de respetar, promover y proteger (ONU, 2011). Así como el derecho a vivir dignamente que se refiere a tener la disponibilidad de servicios, materiales, infraestructura, habitabilidad, accesibilidad, localización y adecuación cultural (ONU, 2011; Brasil, 2013). 
Dentro de la legislación brasileña se encuentran varios textos normativos que protegen el derecho a la vivienda como: la Ley $\mathrm{n}^{\circ} 11.124$, de 16 de junio de 2005 que habla sobre el Sistema Nacional de Habitación de Interés Social y la Ley $\mathrm{n}^{\circ} 11.977$, de 2009 que se refiere al Programa Mi Casa Mi Vida ${ }^{5}$ de la regulación de tierras de asentamientos localizados en áreas urbanas, lo que incluye políticas públicas de inducción al desarrollo socioeconómico (Brasil, 2013). Directrices que deberían regular las medidas que se toman para realizar los procesos de desplazamiento, donde no solo se haga un reasentamiento de lugar, sino que sean procesos de participación en los que haya una gestión compartida con las familias afectadas y así este sea un proceso menos impactante para esta población.

Entretanto, al realizar una revisión de los estudios relacionados con el desplazamiento de familias y el apoyo social en Brasil, se encontraron investigaciones relacionadas más con el apoyo social desde el área de la salud, como en el caso de los adultos mayores (Motta.et. al., 2010) y de las familias de pacientes con cáncer (Sánchez. et.al., 2010), los cuales intentaron hacer análisis más cuantitativos relacionando desplazamiento y apoyo social. Otros estudios encontrados relacionados con estas dos temáticas fueron: redes en jóvenes migrantes (Miranda, Calvino e Martí, 2012), redes sociales y migración (Fazito, 2010) y desplazados internos y derechos humanos en Brasil (Fernandes, 2014).

Esto estudios están intrínsecamente conectados a la exclusión de la población económicamente menos favorecida, articulándose con la utilización de dispositivos estatales para atender demandas de expansión de capital del estado y no de necesidades sociales de las poblaciones. Ejemplo de ese proceso ha sido lo que ocurrió desde el 2013 en la ciudad en que se ha desarrollado este estudio, Porto Alegre (Brasil). En esta ciudad, aproximadamente 14.300 familias fueron directa o

5 Minha Casa Minha Vida, nombre en portugués, es un proyecto del gobierno que ofrece facilidades a familias con baja condición económica. Estas familias deben tener ingresos menores a 1.600 reales e inscribirse en la alcaldía de su ciudad y esperar los sorteos que se realizan para completar los otros requisitos que les exigen. El préstamo no puede ser mayor que el $30 \%$ de los ingresos familiares mensuales. 
indirectamente involucradas en procesos de remoción destinados a obras del Mundial de Fútbol 2014 (muchas de ellas incompletas hasta hoy), obras para eliminación o reducción de riesgo y/o obras relacionadas al desarrollo financiero de la ciudad (Fernandes, 2014).

De acuerdo con los movimientos de defensa a la vivienda y a la relatoría final del Grupo de Trabajo Humano a la Vivienda Adecuada, la desinformación de la población sobre las áreas que fueron despojadas y el destino de las comunidades, fue una táctica de los gobiernos municipales para evitar el enfrentamiento con las poblaciones afectadas (Brasil, 2013), lo que facilita el abandono de sus viviendas por parte de la comunidad y que así se puedan utilizar y "limpiar" los terrenos para proyectos inmobiliarios con fines comerciales. Se trata de una estrategia en todo el territorio nacional que empieza con la desinformación de la comunidad y con una idea que los pobres no saben "lo que mejor les conviene”, en la que alegan que los motivos del desalojo, como lo destaca por la Articulación Nacional de los Comités Populares del Mundial de Fútbol (Copa) (ANCOP): son "favorecer la movilidad urbana, preservar las poblaciones en riesgo ambiental y hasta el mejoramiento de sus condiciones de vida, así sea lo opuesto y sea en contra de su voluntad" (ANCOP, 2012. p. 14).

\section{Asistencia Social brasileña y los procesos de reubicación territorial}

La Asistencia Social brasileña surge como Política Pública por medio de la Constitución Federal de Brasil, en el 1988. Asimismo, el cambio en las perspectivas asistencialistas para la inversión en derechos y ciudadanía se sumó a una serie de estrategias de protección social. La operatividad de ese proceso tiene por marco la Ley Orgánica da Asistencia Social (LOAS) del 1993, que compone la Seguridad Social, Sanidad y Providencia Social brasileña como ejes de inversión pública.

Con el objetivo de garantizar bienestar a la población perteneciente al programa de Seguridad Social surgió la Política Nacional de Asistencia Social y el Sistema Único de Asistencia Social (SUAS), que tuvieron por propuesta dos estructuras de funcionamiento integrado: 
la Protección Social Básica (PSB) - prevención de situaciones de riesgo social, los Centros de Referencia de Asistencia Social (CRASs); y la Protección Social Especial (PSE), que considera acciones de mediana y alta complejidad, teniendo por referencia, los Centros de Referencia Especializada en Asistencia Social (CREAS) que es la unidad pública que ofrece servicios de la protección especial (Brasil, 2010).

Dentro de los programas de la PSB, se destaca el Servicio de Protección y Atención Integral a la Familia (PAIF). El PAIF consiste en el trabajo social con familias, que tiene como finalidad fortalecer las funciones protectoras de la familia, prevenir la ruptura de sus vínculos, promover su acceso y goce de los derechos y contribuir en la mejoría de su calidad de vida. El PAIF supone el desarrollo de potencialidades $\mathrm{y}$ adquisiciones de las familias y el fortalecimiento de vínculos familiares y comunitarios, por medio de acciones de carácter preventivo, protector y proactivo.

Dentro las acciones protectoras del PAIF se pueden destacar acciones territoriales de carácter comunitario. Cuando se evalúa, por ejemplo, el enorme déficit habitacional de Brasil y la amplitud de personas afectadas por desplazamientos forzados en Brasil, lo que lleva a analizar las diferentes formas de violencia para construir alternativas en términos psicosociales desde los aspectos singulares del país. Así, el programa PAIF se relaciona con este estudio, el cual tuvo como objetivo central el análisis cualitativo de los distintos significados que las personas asistidas por este servicio, afectadas por razones habitacionales y que pasaron por diferentes modalidades de desplazamiento en el sur de Brasil, dan a estos procesos.

\section{Método}

Este estudio se apoya en los principios de la investigación cualitativa, en la que se estudia el conocimiento y las prácticas de las personas, se analiza las interacciones y las maneras de enfrentar las situaciones de su cotidianidad (Flick, 2012). Específicamente, se utilizó el estudio 
de caso, con el que se buscó el contraste entre historias, buscando aspectos comunes y características diferenciales sobre el proceso de desplazamiento por el que pasaron familias brasileńas. Los elementos que componen el estudio de caso deben contener características relevantes entre sí, ya sean de semejanzas o diferencias para que a partir de la comprensión que se forma, se contribuya a la formación de una mejor teorización de estos. En este sentido, Chizzotti (2018) afirma que el estudio de caso tiene como propósito conocer y comprender ampliamente los grupos de estudio y desarrollar descripciones teóricas más generales sobre regularidades de los procesos y las estructuras sociales.

\section{Contexto}

Este estudio inició a través de los Centros de Referencia de Asistencia Social (CRAS) que participaron en el 2014 de la investigación mayor de la cual hace parte este proyecto, titulada: "Apoyo social y familiar en familias acompańadas por el Servicio de Protección y Atendimiento Integral a la Familia (PAIF) en Porto Alegre"6 y la cual fue desarrollada en conjunto con el Ministerio de Desarrollo Social (MDS) de Brasil. En el acceso y contacto con estas familias, ciertas peculiaridades como números de teléfonos errados, poco tiempo disponible por parte de los miembros de la familia, falta de espacios físicos en algunos CRAS y factores externos como protestas de este sector, influyeron en las decisiones de abordaje de las familias, lo que llevó a ampliar nuestro contacto hacia a aquellas familias que estaban siendo atendidas por otras entidades que también hacen parte de la Asistencia Social como los Centros de Referencia Especializado de Asistencia social (CREAS) y el Servicio de Atendimiento Familiar (SAF), que también tiene como objetivo atender familias en situaciones de vulnerabilidad, riesgo social o cuyos derechos fueron violados. 


\section{Participantes}

Para la selección de las participantes se tiene en cuenta lo afirmado desde la metodología del estudio de caso, la cual manifiesta que al analizar un contexto o realidad se intenta conocer lo que cada actor tiene por contar, es por esto por lo que se pueden elegir, a través del estudio de caso, sujetos que atiendan a las diferentes circunstancias posibles frente una situación (Jiménez, 2012), siendo considerado el método más apropiado para comprender la realidad de una situación. En este estudio fueron seleccionadas 3 mujeres pertenecientes a familias que vivieron alguna situación de desplazamiento, es decir cada mujer representó un tipo de desplazamiento presente en Brasil. La primera mujer migró por desastre natural, la segunda por causa de mejoramiento urbano y una tercera con desplazamiento "voluntario", quienes vivían en Porto Alegre-Brasil y su área metropolitana. Estas familias debían estar siendo atendidas por la Asistencia Social. En la Tabla 1 se presenta de modo general la caracterización de estas participantes, las cuales fueron entrevistadas en el año 2015, año que evidenció parte de las obras que quedaron inconclusas luego de terminar el mundial de futbol.

\section{Tabla 1}

Caracterización de las participantes

\begin{tabular}{llllll}
\hline N $^{\circ}$ & Nombre & \multicolumn{1}{c}{$\begin{array}{c}\text { Tipo de } \\
\text { desplazamiento }\end{array}$} & Local donde viven & $\begin{array}{c}\text { Con quien } \\
\text { vive }\end{array}$ & $\begin{array}{c}\text { Centro de } \\
\text { referencia A.S }\end{array}$ \\
\hline 1 & Rosa & Naturaleza & $\begin{array}{l}\text { Esteio-RS (área } \\
\text { metropolitana de } \\
\text { Porto Alegre, Brasil) }\end{array}$ & $\begin{array}{l}\text { Hijo y dos } \\
\text { nietos }\end{array}$ & CRAS \\
\hline 2 & Luisa & Estado & $\begin{array}{l}\text { Nueva Chocolotão/ } \\
\text { Porto Alegre }\end{array}$ & Hija & SAF \\
\hline 3 & Constanza & Voluntario & $\begin{array}{l}\text { Barrio Nazareth/ } \\
\text { Porto Alegre }\end{array}$ & $\begin{array}{l}\text { Hijo y } \\
\text { nieto }\end{array}$ & CREAS \\
\hline
\end{tabular}




\section{Medición}

Se ha utilizado como herramienta de investigación la entrevista narrativa, la cual cuenta con algunas preguntas guía para promover el dialogo de las participantes, ya que este procedimiento no cuenta con estructuras prestablecidas sino que permite que las personas cuenten sus experiencias de vida de manera más abierta, que les permite expresar sus percepciones y puntos de vista sobre las situaciones (Flick, 2012). De igual forma, se utilizaron diarios de campo como fuentes de información, toda vez que permiten comparar diferentes visiones del proceso de colecta, documentar el proceso de campo y hechos perdidos en las entrevistas, lo que hace la experiencia más intersubjetiva y explicita para el análisis de datos (Flick, 2012).

Para la entrevista narrativa se siguieron las fases propuestas por Schütze (2011), quien hace meción principalmente de tres etapas y Jovchelovitch, Bauer (2002) quienes basados en Schütze proponen cinco fases (Tabla 2).

\section{Tabla 2}

Fases de la entrevista narrativa

\begin{tabular}{ll}
\hline \multicolumn{1}{c}{ Fases } & \multicolumn{1}{c}{ Acciones } \\
\hline Preparación & $\begin{array}{l}\text { Exploración del campo (en este estudio fue teórica y } \\
\text { experiencial) }\end{array}$ \\
\hline Iniciación & $\begin{array}{l}\text { Formulación del tema inicial para generar la narración } \\
\text { Para nuestro estudio: Me cuentas un poco de tu historia, ¿cómo } \\
\text { fue el desplazamiento? }\end{array}$ \\
\hline Narración central & $\begin{array}{l}\text { No interrumpir } \\
\text { Solamente incentivo no verbal o paralingüístico para continuar } \\
\text { la narración. }\end{array}$ \\
\hline Fases de preguntas & $\begin{array}{l}\text { Solamente preguntas como: ¿y entonces que sucedió? } \\
\text { No emitir juicios de valor }\end{array}$ \\
& $\begin{array}{l}\text { No dar opiniones o preguntas sobre actitudes } \\
\text { En este estudio: ¿Principales cambios que vivió su familia? } \\
\text { ¿Cuál es su percepción de este proceso? }\end{array}$ \\
\hline
\end{tabular}




\begin{tabular}{ll}
\hline \multicolumn{1}{c}{ Fases } & \multicolumn{1}{c}{ Acciones } \\
\hline Cierre & Se va finalizando el encuentro \\
& Se para de grabar \\
& Se hacen algunas preguntas, ¿por qué? de ser necesario. Luego \\
& se toman algunas anotaciones (en este estudio plasmadas en los \\
& diarios de campo). \\
\hline
\end{tabular}

*Adaptación de la teoría al proceso realizado en este estudio.

Durante este proceso se trató de dar prioridad a la narración libre de las entrevistadas, procurando interrumpir lo menos posible y acompañando con la escucha activa. Al ser la entrevista narrativa una herramienta que busca comprender a través del discurso de las personas la realidad social de las mismas, y por tanto no posee una estructura rígida o fija, se plantean algunas preguntas guía que se obtienen de la preparación y revisión realizada teóricamente sobre la temática de interés y que permitieron conocer las situaciones significativas para ellas con relación a la temática. Por tanto, las tres preguntas guía que se establecieron fueron: Me cuentas un poco de tu historia, ¿Cómo fue el desplazamiento? ¿Principales cambios que vivió tu familia? ¿Cuál tu percepción de este proceso?

\section{Procedimiento}

El proceso de recolección de información comenzó con el contacto con los equipos de trabajo de las instituciones de Asistencia Social a través de llamadas telefónicas y correos electrónicos, a quienes después se les solicitó los números telefónicos de las familias que en la investigación mayor se habían identificado como desplazadas, para convidarlas a participar en una entrevista narrativa en la que iban a hablar sobre su proceso de desplazamiento. La entrevista narrativa se inició después de la lectura y firma del Término de Consentimiento Informado y de explicarles el objetivo de la investigación a las familias. Todas las entrevistas 
fueron grabadas y se realizaron en la casa de cada una de las representantes de las familias, teniendo como duración aproximadamente 40 minutos, en los que ellas nos contaron cómo fue el proceso de desplazamiento que vivieron. Durante la entrevista se tomaron algunas fotos con el fin de dejar un registro fotográfico del proceso de aproximación con estas familias y lo que significó para ellas ese desplazamiento.

\section{Análisis de datos}

Para el análisis de datos además de transcribir las entrevistas se utilizó la técnica del estudio de caso, con la que se buscó la comparación entre historias, identificando aspectos en común y características diferenciales sobre el proceso de desplazamiento por el que pasaron estas familias. Para Stake (2000) los elementos que componen el estudio de caso múltiple o colectivo, deben contener características relevantes entre sí, ya sean de semejanzas o diferencias para que a partir de la comprensión que se forma contribuyan a la formación de una mejor teorización de estos, que fue lo que se pretendió hacer en esta investigación. Es por esto que cada mujer da cuenta de un tipo de desplazamiento específico, una ubicación geográfica particular y una figura de atención del centro asistencial diferente, lo que llevó a en cada discurso ir destacando esas narrativas semejantes y diferenciales que aparecieron y mostraban relación con la temática investigada.

Asimismo, en la interpretación de esta información recogida se utilizó el análisis Crítico del Discurso (ACD) el cual reprocha la forma en la cual existe la desigualdad de poder y se mantiene la discriminación que se reproduce a través del discurso. El discurso no solo en sus funciones pragmáticas de persuasión y credibilidad sino también en las funciones sociopolíticas de legitimización y control (Maneri \& Ter Wal, 2005). De esta manera, dentro de las narrativas de las tres mujeres, se comienza por identificar aquellos actos repetitivos y no aislados que relacionan los tres discursos; luego se establecen las instituciones o grupos inmersos involucrados en esas situaciones y que de una $\mathrm{u}$ otra forman abusan de ese poder; también se identifican los relatos que dan cuenta de actitudes inaceptables por partes de los actores, y por 
último los discursos de conformidad o naturalización de las situaciones que los colocaron e vulnerabilidad. Estos pasos, enmarcados en nuestra temática de desplazamiento forzado, y como lo afirma Vandjick (1994) permitieron mostrar la desigualdad e injusticia social de este fenómeno y realizar una discusión sobre el desplazamiento y la labor del Estado frente a este, desde la perspectiva de las familias entrevistadas.

\section{Resultados}

\section{Caso 1 - Rosa}

Rosa es una señora mayor, divorciada, que trabaja en servicios generales de limpieza y se encarga de su hijo y sus dos nietos. Aunque oficialmente se considere su proceso de desplazamiento por riesgo ambiental, Rosa narra una vida de precariedad habitacional, con múltiples desplazamientos y precariedades en su relación con los espacios urbanos. Cuando cuestionada acerca de su situación, Rosa relata que su primer desplazamiento se ha dado por no poseer la posesión legal de su casa - una construcción ilegal que había comprado sin registro notarial. Debido al proceso de urbanización de la comunidad donde residía, se mudó con su familia a una región de más riesgo ambiental.

...he pasado por muchas dificultades, por casi 30 años vivi en un Barrio popular de Esteio (área metropolitana de Porto Alegre) donde tuvimos que salir porque empezaron a urbanizar y no teníamos condiciones para construir cómo la ley determinaba. Así, compramos un terreno en la orilla de arroyo, no teníamos más condiciones, pero tampoco sabiamos que ibamos a pasar tanto riesgo... preguntando y preguntando supe que podía inscribirme para poder entrar en el sorteo de Mi Casa Mi Vida...pasaron más de 3 años y no sabía nada y tampoco sabia que más hacer la casa cada día estaba peor... y nadie informaba nada... (Rosa, desastre natural)

Hace un año vive en un condominio del proyecto Mi casa, Mi vida, después de 11 ańos de vivir en una casa situada en un lugar de alto riesgo natural del área metropolitana de Porto Alegre y en condiciones 
precarias, pues estaba cerca de un arroyo, donde constantemente sufría inundaciones. Ella es quien mantiene sus dos nietos y su hijo que acaba de salir de la cárcel en libertad condicional, quien, además debe lidiar con la discriminación de ser exconvicto.

La casa estaba cayéndose por partes... llovía dentro, el agua entraba por la sala y salia por la cocina, era horrible... yo no sabia si iba a llegar y la casa iba a estar abi o no... mi mudanza fue por necesidad, si no hubiera salido ese sorteo yo me hubiera tenido que ir para otro lugar, para la calle, para aqui o para allá, otro lugar porque ya no teníamos más condiciones de vivir allá... una casita llena de huecos, mosquitos, barro y deshaciéndose por los lados, era horrible... ha sido difícil...cuando yo llegué aqui tenía el lavaplatos, la estufa, alguna ropa y un colchón, el resto lo perdí... esa mesa me la dejó mi cuñada y el resto lo consegui comprar con una financiación que estoy pagando... ahora tengo cuentas por pagar que antes no tenía, pues vivía en una zona de invasión, tengo que pagar condominio, luz, agua, todo eso, pero aun asi agradezco que tengo un techo, aunque me haya traido tantas deudas que no me vea en condición de quitar (Rosa, Desastre Natural).

\section{Caso 2 - Constanza}

La señora Constanza es viuda, tiene 66 años y realiza trabajos informales en diferentes locales. Ha vivido diferentes desplazamientos durante su vida. Vivió en una región de extrema pobreza, donde no conseguía suplir ni sus necesidades básicas, por lo que tuvo que mudarse para otro terreno que quedaba en un callejón donde a veces por la lluvia se desbordaban las alcantarillas y la mayoría de sus cosas se dañaban, incluyendo la estructura física de la casa. De ahí se tuvo que desplazar para el lugar en donde actualmente está viviendo, que es un antiguo salón abandonado donde adecuó una cocina y unas camas, todo en el mismo espacio. La razón de este desplazamiento ha sido la implicación de sus hijos en conflictos con bandas de traficantes de drogas - sea por usuarios, sea por trabajar para una de las facciones, sea por rehusarse a hacerlo. Ella vive con uno de sus 7 hijos y uno de sus nietos. 
...con 11 años fui a trabajar a una pensión, a los 17 años vine a Porto Alegre a buscar empleo sin contrato fijo, en servicios generales, luego pasé de un barrio a otro, lucharla todo el tiempo...esto aqui por lo menos no se cae, tuve que improvisar una estufa y buscar ganar otras cosas, esperar lo que suceda... ¿recibir ayuda? Nunca he recibido, lo único que tengo es Bolsa Familia, me dicen que tengo que reclamar mis derechos, por ser mayor pero no se cuáles son... hace dos meses que estoy aqui, teníamos que arreglar la casa del otro lado porque el patio estaba lleno de agua (...) me subi a este pedazo aqui mientras sale ese negocio allá, aunque allá todo es un barrial... (Constanza, Estadol Violencia urbana).

...mi hijo falleció... lo encontraron muerto en la esquina con un tiro... fue por la droga... el segundo en la cárcel, por ayudar en el tráfico... el cuarto tuvo que fugarse por qué no quiso meterse en esto. Si se quedaba, lo mataban. (Constanza, Voluntario/inseguridad).

...fueron varias las veces que tuve que cambiarme de vivienda, una fue cuando me separé de mi primer marido por causa de la bebida, me incomodaba mucho, él vendía todo para beber, me amenazaba, pegaba a los niños... llegué al callejón donde estaba hace poco, entonces comenzó lo de la "guerra del tráfico", derrumbaron la valla y luego comenzó a inundarse el patio y dañarse algunas cosas, llenarse de hongos, ahi, decidi venirme para acá y agarrar este terreno... mi hijo fue en estos días y ya está todo inundado...

...que puedo decir...yo quería lo mejor, estaba a punto de quedar en medio del agua, aunque me gusta mi pedacito, mis plantas, me gustaba estar allá, pero antes de que sucediera algo grave mejor me sali y aqui pues tengo que esperar lo que va a pasar después, de pronto me tenga que salir también porque esto no es mío... (Constanza, Voluntariol inseguridad).

\section{Caso 3 - Luisa}

Luisa es viuda, tiene 27 ańos y tiene dos hijas: la de tres fue llevada por el Consejo Tutelar de la Infancia por explotación infantil y la otra tiene un año. Durante cuatro años vivió en la calle con su compañero 
de ese entonces, después ellos consiguieron un lote de invasión en el centro de la ciudad, en un terreno del Estado, en las inmediaciones de un parque y oficinas públicas, la llamada "Vila Chocolatáo", por estar al lado del edificio de la delegación del Ministerio de Hacienda, cuyo formato y color recuerda a una tableta de chocolate ${ }^{7}$. En condiciones muy precarias, ahí vivieron un poco más de tres años, se separaron y luego ella fue despojada por el gobierno de Porto Alegre, por las condiciones insalubres en las que se encontraba el barrio, aunque la versión de los moradores del Barrio es que los vecinos "nobles" y el gobierno los quitaron de ahí porque era una mala imagen para la ciudad. Actualmente vive con su hija menor en lo que se conoce como la nueva Chocolatáo, barrio que en un comienzo fue destinado para albergar los moradores de la antigua Chocolatáo ubicado en una de las periferias al noreste de Porto Alegre.

... allá era zona de rico, encorbatado, entonces todo mundo se juntó, fue a la justicia y pidieron para que el Barrio saliera de allá... esa área no era nuestra, solo que nosotros no queríamos desocupar porque no teníamos para donde ir...estaban pidiendo esa área... hicieron una petición firmada por todo mundo, que mandaron quien sabe para dónde y cuándo ya vimos hicieron un reasentamiento para el barrio nuevo... (Luisa, Estado).

...ellos (agentes del poder público) decían que era un área de riesgo, pero nadie entendía que era área de riesgo... ¿Qué es riesgo para ellos? Después del derecho de petición y luego de unos años fuimos reasentados... aqui al principio fue difícil porque no sabiamos dónde estábamos, no conocíamos a nadie ni para donde ir...ni puesto de salud teníamos...(Luisa, Estado).

... antes vivía en la calle, trabajaba reciclando y junto con mi compañero conseguimos comprar una casita por $R \$ 200$ en la vieja Chocolatão, después me quitaron mi hija de 3 años, me dejó mi compañero y vinieron las humillaciones de los vecinos nobles del barrio, vino la petición de desalojo y después de tres años nos reasentaron para aqui, bien lejos del 
centro de la ciudad que era donde vivíamos... A mí marido lo mataron por ir a otro barrio a buscar droga... le dieron dos tiros... fue la semana que pasó... (Luisa, Estado).

...mi vida mudó totalmente... estoy más feliz... allá estábamos mejor ubicados, pero aqui tengo un techo para mi hija... (iQué consejo le daría a otra familia desplazada?)... si le van a dar una casa, la agarre con las dos manos porque después no va tener la misma oportunidad... (Luisa, Estado).

...yo sali de casa a los 9 años, la calle me enseño todo y si tengo esa casa es porque luché para tenerla... fue difícil porque al principio no conocía a nadie, nadie sabia para dónde ir, ni conocían ningún puesto de salud, asistente social ni nada...poco a poco ha mejorado eso... (Luisa, Estado).

\section{Discusión}

El que las personas tengan que abandonar sus hogares y que esto suceda dentro de los límites del territorio nacional, es decir dentro de su propio país, son las dos características que señala el observatorio de desplazamiento interno, para identificar un desplazado interno (ACNUR, 1998).

Estos discursos dan cuenta de una falta de planeación y políticas públicas por parte del Estado frente a situaciones de vulnerabilidad social, como en este caso el desplazamiento forzado, puesto que dentro de las responsabilidades del Estado se encuentra el velar, por encima de cualquier otro interés, por el bienestar de las personas afectadas en estas situaciones de vulnerabilidad (ONU, 2011). Estas declaraciones de las familias dan cuenta de una situación de desigualdad social que venían viviendo estas mujeres mucho antes del evento de desplazamiento, lo que demuestra que los intereses del poder público están más dirigidos a otros proyectos que generan un beneficio para este. Se refleja una discriminación en la distribución del espacio territorial, donde el poder público prioriza las inversiones en gestiones de la ciudad que promueven un desarrollo desigual (Pinheiro, 2015). 
Se puede percibir que las tres familias vivían en condiciones precarias y sus vidas estaban en riesgo - antes y después del desplazamiento. Sus trayectorias ilustran el cuadro de pobreza estructural que afecta a casi un cuarto de las familias brasileñas: ingresos económicos, lugares socialmente vulnerables, terrenos de invasión, en los que terminaron por no contar con más opciones económicas ni sociales. De acuerdo con la relatoría especial de la ONU para la vivienda adecuada, dentro de sus orientaciones se enfatiza en que la vivienda adecuada, para todos los ciudadanos, incluye la garantía de un lugar para vivir sin amenaza de remoción, acceso a los servicios básicos y uso de materiales adecuados que garanticen un espacio protegido contra riesgos (ONU, 2011). Derecho que, dentro del discurso de las mujeres entrevistadas, venía siendo violado desde antes de su proceso de desplazamiento, es decir, el desplazamiento que ellas vivieron fue solo una consecuencia más de un sistema social desigual, el cual han tenido que enfrentar y lidiar durante varias situaciones de sus vidas.

Se percibe además que de una u otra forma la falta de información es un tema constante en las familias que han sido desplazadas. Al verse en condiciones más vulnerables y tener que buscar rápidamente como suplir sus necesidades mínimas para sobrevivir, no se informaban bien sobre sus derechos, es así como para conseguir sobrevivir tuvieron que conformarse con lo que apareciera o les fuera ofrecido, sin tener ni tiempo de evaluar si era lo mejor para ellos o no.

Por otro lado, se puede percibir que estas familias no solo han tenido que pasar por situaciones de violencia simbólica por parte del poder público o de quienes tenían la información de lo que iba a suceder con ellas, sino que también pasaron por otros tipos de violencia que caracterizan los lugares donde ellas estaban ubicadas, barrios populares generalmente apartados y ubicados en la periferia de las ciudades. Son barrios que evidencian los procesos de exclusión social y se definen en parte por la inseguridad social; asociada a crímenes y tráfico de drogas.

Las familias de Rosa y Constanza, por ejemplo, no integraron un proyecto formal de remoción de familias, como sucedió con Luisa que 
pertenecía a los reasentamientos del Barrio Chocolatão, lo que se puede percibir que influenció en los desenlaces de sus desplazamientos forzosos, pues aunque el Estado al parecer tiene registros de las familias y de las áreas que están en riesgo, estas familias al no estar dentro de los terrenos de interés del Estado para futuras obras o proyectos de desarrollo económico o urbanístico, no entran dentro de las ayudas y/o indemnizaciones proporcionadas por el poder público, aunque igual hayan perdido bienes materiales y sus derechos fundamentales no estén siendo protegidos. Esto significó para ellas tener que buscar por sus propios medios las soluciones sobre donde vivir y cómo recuperar sus bienes materiales.

De esta manera y a pesar de que, desde cierto punto de vista, los desplazamientos de estas familias fueron producto de la desigualdad social estructural con la que al parecer ya aprendieron a lidiar, se percibe en sus discursos significados muy similares sobre lo que sucedió en sus desplazamientos. Son discursos que no reflejan insatisfacción con el lugar en el que están viviendo actualmente o que manifiesten negligencias directas por parte del Estado, sino que expresan mejoras con la mudanza.

Se perciben así significados construidos con base en una historia de vida, en su mayoría, cargada de carencias y déficits, donde al parecer les tocó constantemente rebuscar empleos, lugares y condiciones que suplieran algunas de sus necesidades, por lo que al encontrarse con una oportunidad de mejorar algunas de sus condiciones, como la vivienda, ellas no dudaron y aceptaron, así eso implicara adaptarse a otras situaciones, acarrear otras consecuencias para las que no estaban preparadas, como lo es pagar una mensualidad y servicios públicos que antes no pagaban.

Tanto el desplazamiento de personas por obras como los desastres naturales, que son consecuencia de una urbanización excluyente que lleva constantemente a una ocupación de espacios inapropiados para vivir, que terminan siendo riesgosos para las familias, lo que demanda la respuesta del poder público para que repare los dańos provenientes de la catástrofe (Brasil, 2013). Es así como estas familias terminan siendo 
parte de un círculo vicioso que comienza y termina con el Estado, el cual es el que genera el problema, proporciona soluciones parciales que continúan generando más dificultades, ya que en varias de las situaciones no involucra la participación de los grupos vulnerables en la planeación de desarrollo de proyectos públicos.

Los desplazados enfrentan, entonces, cierta desterritorialización producto de la limitada participación que esta población tiene en la realización de los proyectos de inversión que los afectan directa o indirectamente, ni en la elección de los lugares a donde van a ser removidos. Como ya afirman Tomé y Casillas (2016), cuando el beneficio económico se convierte en el objetivo mayor en los desplazamientos forzosos, aunque sean personas, se les expulsa, se les indemniza miserablemente tras arduo regateo; se les condena a la marginación cultural - pues siempre serán "desplazados". "Se les penaliza obligándoles a desarrollar nuevos trabajos en lugares que previamente han sufrido un inevitable deterioro ecológico al "implantar" nuevas poblaciones que lo han alterado significativamente" (p. 126).

Otro dato importante en estas acciones estatales es la forma cómo se dan las relaciones con las familias desplazadas - de manera autoritaria y sin respetar su condición ciudadana de ser informado de sus derechos. En este sentido, como afirma Gonçalves y Vargas (2015) es a través de la tecnificación del discurso y ciertas prácticas utilizadas, por el poder público, que se establece una política basada en la violencia simbólica, la cual destituye de cualquier poder de decisión a los afectados por los desplazamientos compulsivos. De igual forma Bourdieu (2014) afirma que las relaciones de comunicación, también son relaciones de poder que dependen de la forma y el contenido de los sujetos o instituciones, para acumular poder simbólico y volverse instrumentos de imposición o de legitimización de la dominación de una clase sobre otra (violencia simbólica). Que en palabras de Martín-Baró contribuye a la construcción de la estructura ideológica social de un régimen sociopolítico capitalista en el que la división de clases es primordial, la existencia reprimida en sus necesidades básicas y el saber es propiedad de unos pocos (Blanco, 1998). 
Como afirman varios de los documentos en defensa de los desplazados por remociones forzadas, la desinformación es parte de la estrategia del Estado para evitar reclamaciones y enfrentamientos de los afectados frente a los impactos que puede generar este proceso en la población (Brasil, 2013; ANCOP, 2012; ONU, 2011).

Uno de estos impactos, a veces subvalorado en los análisis del déficit habitacional en Brasil, es la violencia coyuntural. Como lo afirma Abramoray y colaboradores (2002) la violencia puede manifestarse desde tres perspectivas: directa, indirecta y simbólica; claramente en las narraciones anteriores de estas mujeres, sus familias también pasaron por una violencia física, al parecer producto de grupos criminales. Estas y otras situaciones que fueron emergiendo durante las entrevistas, dan cuenta de la naturalización de la violencia y de la desigualdad social que ha asumido esta población a lo largo de su historia y vivencias. Es por esta razón que se percibe que con el proceso de desplazamiento y sus consecuencias, estas mujeres parecen por un lado estar afectadas pero por otro estar agradecidas, pues "por lo menos tengo un techo donde dormir". Esto también enuncia, nuevamente, la planeación estatal en la que solo se benefician sectores privilegiados y se atemoriza a la población popular a través de acciones sistemáticas llevadas a cabo por la propia fuerza pública y comunitaria (policía, ejército, grupos organizados o Estado, etc), que marcan claramente el terrorismo del Estado (Chomsky, 2017) que lleva a la internalización del temor y aceptación de la desigualdad social.

Estos discursos evidencian la ambivalencia que se percibió en varias de las afirmaciones de estas familias. Puesto que aunque dos de los tres casos terminaron en un final en el que ellas "ganaron" un beneficio del Estado, también está el caso de Constanza que representa los otros casos de familias que continúan siendo afectadas por eventos extremos y por una ausencia de respeto de los derechos. Como afirma Pinheiro (2015) son familias pobres que deben enfrentar una serie de eventos difíciles, una cadena de consecuencias que visibilizan las injusticias y conflictos que existían antes de los mismos eventos "naturales", consecuencia del modelo de desarrollo brasileño. Lo que debería ser un 
derecho al que todos deben accesar sin tantos requisitos y burocracia; las familias lo ven como un sorteo y/o suerte del destino donde solo algunos son los beneficiados, otros beneficiados parcialmente y otros que continúan en la misma situación de precariedad, como una de ellas lo dijo: es un sorteo y no se debe soltar.

Dentro de las narrativas institucionales acerca de los desplazamientos forzados, también se encuentra como argumento el preservar las familias de riesgos ambientales. Familias que pueden ser afectadas por proyectos de mega emprendimientos como hidroeléctricas, por inundaciones o mudanzas climáticas. Es el caso de una de las familias entrevistadas en este estudio, que de un día para otro quedaron sin un techo. Estas familias pertenecientes al área metropolitana de Porto Alegre terminaron siendo desplazadas por un "evento de la naturaleza", pero como afirma Gonçalves y Vargas (2015) los desastres adjetivados como naturales también ocultan complejas relaciones sociales de desigualdad históricamente producida.

Los desastres son, entonces, fenómenos sociales que merecen también la atención del Estado, comunidad y organizaciones. De acuerdo con Valencio (citado por Gonçalves \& Vargas, 2015) hay tres elementos que deben ser cuestionados en relación a los desastres: 1. Se persiste en el fenómeno como un evento amenazante que ocurrió en un día específico y no se consideran las razones sociales y políticas que condujeron al desastre; 2. El esfuerzo por demostrar el regreso a la normalidad termina desplazando la opinión pública sobre las causas estructurales de los desastres y oculta la realidad de aquellos directamente afectados por el evento y la precaria respuesta que tienen los poderes públicos frente al problema; 3. El uso del término desastre natural tiende a resaltar que los factores de amenazas naturales serian incontrolables, lo que deja de lado el hecho que parte de los impactos urbanos de esas amenazas están explicados en las desigualdades ambientales y sociales de las ciudades (Gonçalves \& Vargas, 2015). Como afirma Pinheiro (2015), los desastres son consecuencia de falta de políticas que mejoren el acceso a derechos fundamentales como la vivienda, en donde el riesgo es utilizado como justificación para la intervención política, la mayoría de 
veces violando aún más los derechos de la población y fortaleciendo la segregación de la ciudad, movilizando millones de personas (Pinheiro, 2015).

En relación a la contención de esta problemática, también existen diferentes instrumentos legales que pretenden velar y regular la atención de poblaciones afectadas por los desastres, como es la Ley $n^{\circ} 12.608$, de 10 de abril de 2012 que instituye la Política Nacional de Protección y Defensa Civil (PNPDEC) dentro de la cual se destaca la incorporación de reducción de riesgos de desastre, el combate a la ocupación de áreas ambientales vulnerables y de riesgo y la promoción de reubicación de la población residente en esas áreas (Brasil, 2013). Pero a pesar de estas regulaciones estos fenómenos no dejan de traer consigo acciones que violan sus derechos y que son producto de deficiencias en el sistema social, en donde el poder público muestra mayor interés por los beneficios financieros de algunos y no por las consecuencias que deben enfrentar las comunidades, violentando sus derechos fundamentales.

\section{Consideraciones finales}

Esta investigación permitió acercarse y conocer un poco sobre la desigualdad social y violación de derechos por la que pasan las familias desplazadas, derechos proclamados en las diferentes leyes de Brasil donde se enfatiza en el respeto a la vivienda, a la cultura y la prevención de habitad de áreas de riesgo, entre otros y que en varios de estos procesos pasaron hasta desapercibidos. Se percibió que fueron procesos superficiales, en cuanto a un abordaje integral, que fueron planteados para beneficiar a ciertos sectores socioeconómicos pero que estaban lejos de beneficiar a las familias como principales actores de estos procesos.

Dentro de las narraciones de estas mujeres, también, aparece insuficiencia de políticas públicas específicas que direccionen planes de contingencia integrales frente a situaciones como los desplazamientos forzosos, al interior de Brasil, que no solo incluyan y protejan los grandes eventos en los que el Estado tiene pensado invertir y en los que muchas personas se ven involucradas y afectadas, sino que también hayan delineamientos que contemplen aquellos casos particulares, 
como sucedió en dos de las tres familias entrevistadas, que fueron casos "aislados" donde no recibieron atención por parte del poder público y que terminaron resolviendo por sus propios medios la situación de desplazamiento y no porque realmente hayan recibido algún tipo de guía o apoyo por parte del Estado.

Sin embargo se reconoce el trabajo que realizan algunas de las instituciones públicas encargadas de velar por las poblaciones en riesgo de vulnerabilidad, como es el caso del trabajo que se hace dentro de las estructuras de Asistencia Social de Porto Alegre, en donde se cuenta tanto con psicólogos como con asistentes sociales y otros técnicos, quienes intentan realizar una aproximación al seguimiento integral de las familias vulnerables socialmente, pero que hasta ellos mismos reconocen, no es suficiente para abordar toda las poblaciones con tan diferentes necesidades, lo que da cuenta de la importancia de activar o contar con más redes de apoyo especializadas en la temática.

Por lo tanto, se recomienda que las familias desplazadas reciban una atención integral y específica para cada condición en la que se encuentran, como por ejemplo en los momentos posteriores a la reubicación, donde la familia está en un proceso de duelo, intentado superar la perdida de aquel que siempre fue su hogar (así las condiciones físicas no fueran las mejores) y aceptar su condición actual con todo lo que eso acarrea. Es en esos momentos que se considera que podría haber un plan específico de contención para familias desplazadas, el cual cuente con diferentes instituciones integradas, protocolos de atención, espacios de escucha que faciliten la superación de ese "duelo" y donde se le proporcione información pertinente para estas familias que les permita la construcción de nuevas redes sociales y así vivir un mejor proceso de adaptación.

Con respecto a las limitaciones que posiblemente tuvo el estudio, una de ellas fue la ubicación geográfica y situación social de las viviendas de las entrevistadas puesto que eran barrios o locaciones de la periferia o fuera del casco urbano a las que no era tan fácil accesar y que eran consideradas socialmente de cuidado, y al ser la investigadora principal extranjera, se debió realizar los acercamientos con más cautela y en días 
y horarios determinados por las mismas participantes. De igual forma se podría tomar como limitación el tiempo en que acontecieron los desplazamientos puesto que no fueron al mismo tiempo y por la misma causa, y aunque para este estudio esta diferencia fue un punto a favor para el análisis del estudio de caso, para el caso de pretender generalizar o platear una política pública no sería tan conveniente.

Por último, se sugiere como propuesta de investigación futura desarrollar una investigación relacionada con la otra cara de la moneda: los funcionarios de asistencia social y sus percepciones sobre el acompañamiento que se le brinda a las familias que son desalojadas.

\section{Referencias}

Abramovay, M., Castro, M. G., Pinheiro, L. C., Lima, F. S., \& Martinelli, C. C. (2002). Juventude, violência e vulnerabilidade social na América Latina: desafios para politicas públicas. Brasília: UNESCO.

ACNUR - Alto Comisionado de las Naciones Unidas para Refugiados. (1998). Principios Orientadores de los desplazamientos internos. Recuperado de: http://www.acnur.org/t3/fileadmin/scripts/doc. php?file=t3/fileadmin/Documentos/BDL/2001/0022

ACNUR - Alto Comisionado de las Naciones Unidas para Refugiados. (2014). Quem Ajudamos. Recuperado de http://www.acnur.org/ t3/portugues/quem-ajudamos/deslocados-internos/

ACNUR - Alto Comisionado de las Naciones Unidas para Refugiados. (2015). Mundo en Guerra: Tendencias globales desplazamiento forzado en 2014. Recuperado de http://www.acnur.org/t3/ fileadmin/scripts/doc.php?file=t3/fileadmin/Documentos/ Publicaciones/2015/10072

ANCOP - Articulação Nacional dos Comites Populares da Copa. (2012). Dossie de Megaeventos e Violaçóes de Direitos Humanos no Brasil. 2. ed. Recuperado de http://www.apublica.org/ wpcontent/uploads/2012/01/DossieViolacoesCopa.pdf. 
Alexandri, G., González, S., \& Hodkinson, S. (2016). Geografías del desplazamiento en el urbanismo de América Latina. Revista INVI, 31(88), 9-25

Brasil. (2013). Secretaria de Direitos Humanos. Conselho de Defesa dos Direitos da Pessoa Humana (CDDPH) relatório final setembro/2013. Grupo de trabalho direito humano à moradia adequada. Resoluçōes no 09/2011 e nº 6/2012.

Bourdieu, P. (2014). Espaço social e poder simbólico: Coisas ditas. São Paulo: Brasiliense.

Cardoso, A. L., Aragáo, T. A., \& Jaenisch, S. T. (2017). Vinte e dois anos de politica habitacional no Brasil: da euforia à crise, 1, 15-48.

Chomsky, N. (2017). Quem manda no mundo?. Editora Planeta do Brasil.

Do Nascimento, C. A. S., de Albuquerque Vianna, M., Ramos, D. A. L., Villela, L. E., Francisco, D. N., \& Junior, R. I. (2018). A migraçáo do campo para os centros urbanos no Brasil: da desterritorialização no meio rural ao caos nas grandes cidades/ Migration from the countryside to urban centers in Brazil: from deterritorialization in rural areas to chaos in big cities. Brazilian Journal of Development, 4(5), 2254-2272.

Flick, U. (2012). Introducción a la Investigación Cualitativa. Madrid: Morata.

Fernandes, M. K. (2014). Deslocamentos internos e direito à moradia no contexto dos megaeventos esportivos no Brasil: Direitos humanos relativizados pela colonialidade do poder (Dissertação mestrado). São Leopoldo: UNISINOS.

Gonçalves, R. S. \& Vargas, D. (2015). Desastres e Justiça ambiental: Um Desafio para o Serviço. O Social em Questão, XVIII(33), 9-22. Recuperado de http://osocialemquestao.ser.puc-rio.br/ media/OSQ_33_Apresenta\%C3\%A7\%C3\%A3o.pdf

Jiménez, V. (2012). El estudio de caso y su implementación en la investigación. Rev. Int. Investig. Cienc. Soc. 8(1), julio 2012. 141-150. 
Jovchelovitch S, Bauer MW. (2002). Entrevista narrativa. In Bauer MW, Gaskell G., Pesquisa qualitativa com texto, imagem e som: um manual prático (pp. 90-113). Petrópolis: Vozes.

ONU - Organización de las Naciones Unidas. (2011). Guia como atuar em projetos que envolvem despejos e remoçōes? Relatoria Especial da ONU para o Direito à Moradia Adequada. Recuperado de http://issuu.com/unhousing/docs/guia_portugues/1

Pacheco-Coral, A. D. P. (2018). Statelessness, exodus, and health: forced internal displacement and health services. Cadernos de Saúde Pública, 34, e00027518.

Pinheiro, F. (2015). A atuação do INEA no Vale do Cuiabá, Petrópolis, RJ: remoçôes e violaçóes de direitos como justificativa de proteção à vida dos afetados. O Social em Questão, XVIII(33), 215-238. Recuperado de http://osocialemquestao.ser.puc-rio. br/media/OSQ_33_8_Pinheiro.pdf

Ramos Vidal, I. (2018). Desplazamiento forzado y adaptación al contexto de destino: el caso de Barranquilla. Perfiles Latinoamericanos, 26(51), 301-328.

Schütze, F. (2011). Pesquisa biográfica e entrevista narrativa. In: Weller, Wivian; Pfaff, Nicole. Metodologias da pesquisa qualitativa em educação. 2. ed. Petrópolis, RJ: Vozes.

Stake, R. E. (2000). Qualitative: Case Studies. In N. K. Denzin \& Y. S. Lincoln (Orgs.). Hand book of Qualitative Research (pp. 210-222). London: Sage.

Tomé, P. \& Casillas, M. Á. (2016). Escondidos, desplazados, olvidados: la construcción de la presa de El Zapotillo en Jalisco, México. Ambiente \& Sociedade, 19(4), 137-152. https://dx.doi.org/10.1 590/1809-4422asoc0094r1v1942016

Van Dijk, T. (1993). Principles of Critical Discourse Analysis. Discourse and Society 4(2), 249-283. London: Sage.

Recibido: 2019-10-02

Revisado: 2021-03-25

Aceptado: 2021-04-07 